Bibliotecas. Vol 38, № 2, julio - diciembre, 2020. EISSN: 1659-3286

URL: http://www.revistas.una.ac.cr/index.php/bibliotecas/index

DOI: http://dx.doi.org/10.15359/rb.38-2.2

Licencia: Creative Commons (BY-NC-SA) 4.0 Internacional

\title{
La fotografía como método de ilustración de un libro álbum
}

\author{
Photography as an Illustration Method of an Album Book
}

\author{
Jairo Guadamuz-Villalobos* \\ Universidad de Costa Rica
}

ORCID ID: https://orcid.org/0000-0002-0284-3656.

\begin{abstract}
Recibido: 03 de febrero de 2020
Aceptado: 13 de marzo de 2020
\end{abstract}

Publicado: 21 de julio de 2020

\begin{abstract}
Resumen
En este artículo se estudia la relación estrecha que conserva el texto y la imagen, con especial atención a las obras ilustradas denominadas libro álbum. Se aborda, además, el papel que juega la imagen en los procesos cognitivos, así como su papel discursivo y narrativo. Se hace un repaso histórico sobre la fotografía y se estudia su capacidad de reproducción de la realidad. Desde estas reflexiones se expone la importancia de la imagen dentro de la animación lectora y se enfatiza el uso de la fotografía como método de ilustración para obras literarias. Además, se describe el proceso de reilustración de la obra La Guardiana de la naturaleza y sus amigos salvan el río, mediante la reproducción a escala de sus personajes y escenarios para la posterior captura de estos. Así mismo, se detalla el proceso de diagramación de la obra y el producto final obtenido.
\end{abstract}

Palabras clave

Animación lectora / Libro álbum / Ilustración / Fotografía / Diagramación / Reproducciones a escala / Bibliotecas.

\begin{abstract}
The close relationship between the text and the image is studied, with special attention to the illustrated works called the album book. It also addresses the role that the image plays in cognitive processes, as well as its discursive and narrative role. A historical review is made about photography, and its ability to reproduce reality is studied. From these reflections, the importance of the image in reading animation is discussed and emphasis is placed on the use of photography as a method of illustration for literary works. In addition, the process of re-illustration of the work The Guardian of Nature and her friends save the river is described, through the reproduction at scale of her characters and scenarios for the subsequent capture of them. It also details the process of diagramming the work and the final product obtained.
\end{abstract}

\section{Keywords}

Reading animation / Album book / Illustration / Photography / Diagramming / Scale reproductions / Libraries. 


\section{Introducción}

En la Sociedad de la Información y Conocimiento (SIC) el uso de la imagen se ha convertido en una prioridad, en especial en los procesos de enseñanza y aprendizaje. Las Tecnologías de Información y Comunicación (TIC) han cambiado las formas de aprender y han vinculado fuertemente estas actividades con el uso de la imagen. Hoy, la niñez y la juventud demandan conexión a Internet y dispositivos móviles, situación que llega al aula y obliga a cambiar las estrategias didácticas ofrecidas hasta el momento (Sánchez, 2009). Es en el uso de la mayoría de las tecnologías que la imagen cobra fuerza, debido a las posibilidades de consumo de fotografía, cine y video que ofrecen. El usuario ha transformado la forma en la que consume información, adaptándose de mejor manera al contenido relacionado con la imagen.

El uso apropiado de la imagen produce en el estudiantado mensajes de fácil recordación frente a aquellos que son emitidos verbalmente; la fotografía, el cine, la televisión y el computador, entre otros, utilizan la imagen como medio para transmitir mensajes que, aplicados bajo estrategias pedagógicas apropiadas en el aula, posibilitan la enseñanza y el aprendizaje de una manera más agradable y significativa (Sánchez, 2009).

Esta facilidad que aporta el uso de la imagen en el proceso de educativo se debe a los hábitos de consumo que las nuevas generaciones han adoptado mediante el uso de las TIC. Las aulas se enfrentan a estudiantes acostumbrados a información digitalizada, música, animaciones e imágenes en movimiento; estudiantes que se sienten cómodos consumiendo información no lineal (UNESCO, 2013).

Si bien, la lectura está asociada al texto y, en ocasiones, ese texto viene acompañado de ilustraciones, la imagen por sí misma tiene su propio discurso y aporta contenido aún sin necesidad de estar acompañada por texto. La imagen amplía las posibilidades de lectura, pues permite la comprensión de una obra que no es solo textual, apoyando la construcción mental que realiza el lector a través de la imaginación; además, debe tenerse presente que, así como lo afirma Higuera (2016):

...la imaginación es un elemento dinámico, activo y participativo fundamental en el diálogo lector obra, transformador de una realidad, que exalta la individualidad del pensamiento y mantiene a la realidad en una apertura importante hacia la posibilidad y el asombro. (p. 91) 
Por lo tanto, contar con la imagen como apoyo a la lectura incentiva la imaginación y, a la vez, a una interpretación más compleja del contenido de una obra. Este proceso de apoyo no solo se vincula con la construcción mental de una escena, sino con los procesos de enseñanza y aprendizaje que se persiguen en el ejercicio de la animación lectora. Según Delgado (2014):

La imagen tiene un papel muy importante en el proceso de enseñanza-aprendizaje de los niños y niñas. No sólo las palabras contienen información, los niños antes de que entren al colegio y aprendan a leer, ya interactúan con el código visual a través de carteles, anuncios, etiquetas o el cine y la televisión con gran poder comunicativo, que tienen que aprender a interpretar. (p. 9)

Fajardo (2014) insiste en que el uso de imágenes en la lectura le exige al lector participar de forma activa en el relato, lo que trae consigo diferentes beneficios en el desarrollo cognitivo del niño. Por otro lado, Chiuminatto (2011) afirma que existe una estrecha relación entre la imagen y el texto y que este vínculo converge en la imaginación del lector, por lo que ambos interactúan de forma combinada en la mente de quien realiza la lectura; es decir "en el caso de las relaciones texto-imagen, entonces, de lo que hablamos es de relaciones entre parientes, cuyo ancestro común podríamos decir que es la imagen mental" (Chiuminatto, 2011, p. 63).

En la actualidad existen diferentes actividades que vinculan la animación lectora con la imagen; una de ellas es el álbum ilustrado o libro álbum (Higuera, 2016). Este tipo de obra es una manifestación en la cual la imagen llega a tener la misma participación que el texto escrito. Así lo define Fajardo (2014):

El libro-álbum, más que un libro, es un objeto artístico con capacidad narrativa que se vale de un lenguaje híbrido compuesto de imagen y texto, estructurado a través del diseño gráfico y que observa rasgos propios de la metaficción (exceso, indeterminación y subversión de la forma narrativa). (p. 57)

La idea de ilustrar un texto nace a mediados del siglo XVII, en manos de John Amos Comenius, en la obra Orbis Pictus, dedicada a la enseñanza de latín a los niños (Higuera, 2016). Esta obra es considerada el primer libro con características propias para el apoyo de la educación visual. 


\section{El libro álbum y la relación texto-imagen}

El libro álbum es un documento cuyo texto es coprotagonista de la imagen. Ambos tienen un papel importante en la comunicación del mensaje. Así lo indica la Unidad de Currículum y Evaluación del Ministerio de Educación de Chile (2007) cuando afirma que: "esta es, probablemente, su característica principal, el que ambos lenguajes sean complementarios. Esto significa que tanto el texto como la imagen participan en la generación del sentido de la obra" (p. 7). Se trata, por lo tanto, de un documento en el que, si se retira el texto la imagen deja de tener el mismo significado $y$, si se retira la imagen, el texto puede tener otro significado también.

Este acompañamiento que logran tener no es accidental; la imagen y el texto tienen diferentes características en común: ambos intentan abordar una temática o un relato y los dos recursos se abordan desde una perspectiva discursiva en la cual el escritor o el artista intentan comunicar una idea o un conjunto de ellas para expresar sus sentimientos y pensamientos subjetivos en una cuartilla de hoja o enmarcada en los cuatro lados del encuadre de una imagen.

Macedo (2011) decide analizar la combinación del texto con la imagen mediante la relación que la fotografía tiene con la literatura. Al respecto afirma que "la literatura tanto como la fotografía, ante todo, es un testimonio. Cuando se muestra algún sujeto o hecho, se construye un significado, se hace una elección, se elige un tema y se cuenta una historia" (p. 1).

Indistintamente de la técnica de construcción de imágenes, en el libro álbum la persona lectora para interpretar la obra necesita de la lectura de imágenes y textos para poder aprehender lo que realmente se está contando. A diferencias de otro tipo de libros donde la imagen solamente acompaña el contenido textual, en el libro álbum la imagen necesita del texto y viceversa (Colomer, 2005). Esta característica reconfigura la obra de forma tal que su construcción debe asegurar esa participación equitativa, la cual no se basa en la simple presentación gráfica (si contiene más texto que imágenes o al contrario), sino que lo hace basándose en el peso de comunicación que aportan los dos. Puede considerarse que la ilustración que alberga el libro álbum es también texto, y que su lectura va de la mano con todos los elementos de diseño que se hayan seleccionado para el mismo: el tamaño de la 
letra, los colores y la diagramación del documento en general (Unidad de Currículum y Evaluación, 2007).

La característica más notoria del libro álbum es su complejidad, pero esta misma complejidad lo convierte en un instrumento sumamente útil para las actividades de promoción a la lectura, ya que permite un primer acercamiento al hábito de la lectura que, poco a poco, se irá incrementando hasta dotar de mejores capacidades lectoras a quien lo consulta. Al respecto, Hoster y Gómez (2013) afirman que: "El álbum ilustrado es un producto estético, artístico y, a menudo, didáctico: narra historias o nos transmite emociones, pero también constituye un material ideal para formar lectores competentes, capaces de enfrentarse a obras complejas" (p. 66).

Se trata de una obra que combina lenguajes para contar una historia en particular, y estos lenguajes combinados (texto e imágenes), aportan cada uno por separado la posibilidad de interpretar el relato de forma única y personal. Tanto la imagen como el texto permiten una lectura identitaria individual que cada lector puede construir desde su propia experiencia de vida. Al respecto, Abad (2012) afirma que:

La imagen nos vincula a un imaginario que es nuestro "ser en el mundo" como identidad propia y auto-construida. Y la palabra (el texto en general) también es un vínculo que desenrolla el ovillo de las ideas, deseos o saberes para trazar su propio significado (p. 2).

La combinación de estos dos lenguajes crea una obra con una amplia posibilidad de interpretación, constituyendo al libro álbum como una herramienta sumamente útil en actividades de animación lectora, pues el proceso imaginativo que se desarrolla a partir de la lectura se ve apoyado de forma simultánea por los dos lenguajes utilizados.

Se ha planteado con anterioridad que la imagen está presente de forma importante en los hábitos de consumo de las nuevas generaciones, por lo que su uso en la literatura llama la atención de estos nuevos lectores y les facilita la consulta de la obra que la contenga. Se puede incluso contrastar el libro álbum con fuentes de entretenimiento presentes en la actualidad. El cine, por ejemplo, es uno de los espacios de entretenimiento comparado con el libro álbum porque: "se trata en todo caso de entender que, a semejanza del cine, o más precisamente del documental como género cinematográfico, la palabra y la imagen se 
complementan superando las murallas ilusorias de la súper-especialización del arte plástico" (Puerto, 2015, p. 44).

Si es comparable la complementariedad del texto y la imagen dentro del libro álbum con el mismo proceso que se desarrolla en el documento cinematográfico, es posible comparar la capacidad de llamar la atención que podría tener el libro álbum en las actuales poblaciones usuarias-consumidoras de información y entretenimiento. Por lo tanto, la producción de un libro álbum viene a introducir el escenario visual en las actividades de animación lectora sin incluir otro elemento más que la obra por sí misma. En el caso particular de la presente investigación, al contar con la posibilidad de integrar contenidos adicionales mediante el uso de Realidad Aumentada (RA ○ AR por sus siglas en inglés), permite aprovechar las bondades de los contenidos audiovisuales para captar la atención de la persona lectora sin la necesidad de contar con elementos adicionales a la obra.

Sin embargo, el libro álbum es una obra que no tiene límite de edad para su disfrute ya que es apreciada tanto por niños, jóvenes y adultos (Hoster y Gómez, 2013). Aun así, es importante tomar en cuenta que las ilustraciones incluidas en la obra si pueden definirse de acuerdo con la edad de un público meta en particular. La combinación de colores, el nivel de detalle en el dibujo, el realismo de la imagen y la complejidad de los trazos pueden manifestarse de forma diferente si se trata de un libro infantil, por ejemplo, o una obra destinada a un público juvenil o adulto. En síntesis, como tipo de documento el libro álbum puede crearse para cualquier grupo etario, su contenido e ilustraciones son quienes definen el público meta en particular.

La construcción de un libro álbum debe tomar en cuenta la importancia de la imagen que la literatura consultada menciona. La imagen, por lo tanto, debe construirse con el mismo cuidado y la misma dedicación con la que el autor escribió su obra, ya que, a diferencia de un libro ilustrado, en el libro álbum la obra escrita y las imágenes se fusionan en un mismo producto. Se trata entonces de una obra artística y literaria conjunta, una mezcla de letras e imágenes como una sola unidad, cuya lectura está pensada para realizarse de manera vinculada. Para ello es necesario que las personas escritora e ilustradora trabajen de manera coordinada para lograr una correcta fusión de sus obras artísticas. Al respecto, Puerto (2015) afirma que: 
La integración en un mismo nivel de imagen y de escritura exige de los autores, todavía separados entre ilustradores y escritores una adecuación estética. Tal como el poema, el libro-álbum, impone una relación armónica entre las partes y el todo, una estructura que implica una simbiosis de lenguajes no dada por medios técnicos (como el cine o el video). No se trata en este caso de una imagen y un guion, se trata de una imagen abierta y de un texto abierto que precisan fusionarse para generar significados. (p. 44)

Estas afirmaciones sugieren que la fotografía que se capture para las nuevas ilustraciones de la obra elegida (La guardiana de la naturaleza y sus amigos salvan el río), debe elaborarse bajo la premisa de que su contenido cuente una historia; es decir, exista un valor discursivo y argumental en la escena retratada y que cada acción descrita en texto por la autora Sheffield esté debidamente complementada por la ilustración que la acompaña. Para comprender con más detalle esta construcción se abordan en el siguiente apartado los pormenores del uso de la técnica fotográfica para la ilustración de obras escritas.

\section{Fotografía como técnica de ilustración literaria}

La fotografía fue anunciada al mundo el 19 de agosto de 1839, y desde entonces puede ser concebida como ciencia y al mismo tiempo como arte (Ríos, 2009). Se trata de una representación de la realidad mediante la captura de luz en un sensor o una película. El resultado de esta captura es reproducido en medios impresos o digitales y constituye la documentación gráfica de un escenario, evento o persona enmarcados en un encuadre elegido previamente por la persona fotógrafa.

Sin embargo, más allá de la definición técnica, la fotografía constituye todo un fenómeno social, aporta un discurso dentro del encuadre que está íntimamente vinculado con la intención de su creador. Este discurso responde a una interpretación de la realidad que la persona profesional en fotografía espera transmitir mediante su captura a aquellos que exponga su obra. Suárez (2008) explica la complejidad de la fotografía con la siguiente afirmación:

La fotografía está en el centro del proceso de la modernidad, en la nueva relación que el hombre establece con el tiempo, el espacio, la tecnología, la memoria, la muerte y la vida. La visión del otro y de uno mismo, la destrucción y reconstrucción del entorno próximo, la relación con la cultura extraña -ajena-, la corporalidad modificada con los años en relación al retrato de antaño. (p. 15) 
La fotografía, entonces, es una herramienta capaz de reproducir la realidad y de incluir un discurso que apoya o desvirtúa esa realidad retratada, tal y como se aprecia en medios de comunicación masiva en la cual una fotografía puede hacer parecer a un grupo de personas como multitud o como una pequeña reunión informal, según el ángulo y la perspectiva con la que se tome. Según Sontag (2006), las fotografías:

son de hecho capaces de usurpar la realidad porque ante todo una fotografía no es sólo una imagen (en el sentido en que lo es una pintura), una interpretación de lo real; también es un vestigio, un rastro directo de lo real, como una huella o una máscara mortuoria. (p. 216)

El discurso que acompaña la fotografía es indispensable que sea construido con la consciencia del impacto que puede tener en la persona lectora, es decir, debe tomarse la fotografía teniendo clara la responsabilidad que trae consigo en los procesos de comunicación. De hecho, en la fotografía pueden identificarse hasta cuatro fuerzas diferentes, en el caso del retrato de personas, converge la fuerza de lo que el retratado cree que es, lo que quisiera que quienes vean la foto crean que es, lo que el fotógrafo cree que es y lo que realmente interpretan las personas a las que se le exhibe la obra (Barthes, 1990). Y es que, el mismo Barthes, afirma que en el proceso de captura de una fotografía todo aquello que está siendo retratado se convierte en objeto, incluso las personas. Por lo tanto, a la hora de elegir la fotografía para exponer un discurso, o ilustrarlo, puede afirmarse que la idea central de ese discurso se convierte en objeto, se materializa fuera de la mente y se convierte en un elemento con más posibilidades de interpretación y reflexión que la idea abstracta.

Del mismo modo, esta fuerza interpretativa que tiene la fotografía aporta la preocupación de perseguir la objetividad en el retrato y de ser alcanzada; esta objetividad puede verse como una potencial aliada en la forma en la que se comunica una idea. En el caso de obras escritas, la fotografía constituye una herramienta de peso para el enriquecimiento de un relato, o incluso la construcción del relato mismo. Se trata, entonces, de la creación de fotografías que cuenten historias.

Esta capacidad narrativa de la fotografía le permite vincularse de forma complementaria a textos que ofrezcan una historia que contar. Por lo tanto, ilustrar obras escritas con fotografías ofrece la oportunidad de contar con dos fuentes narrativas combinadas, de 
manera tal que el recorrido en la trama se convierte en una experiencia enriquecedora para el lector. Como resultado la imagen y el texto se unen para compartir juntos un relato. Al respecto Gutiérrez (2013) afirma que:

La relación entre literatura y fotografía se establece desde la perspectiva de la narrativa. El término «narrativa» tiene diversas connotaciones, por lo general, se habla de ella como un recurso, el cual está conformado por un enunciado y cuya función del contenido consiste en relatar, es decir, contar una historia. (p. 1)

Por otra parte, el modelo utilizado en la fotografía periodística, y que Bourdieu (2003) estudia a plenitud, sugiere nuevamente el peso que tiene la imagen para contar un hecho real. Para efectos de esta investigación se usaría esa capacidad comunicativa para contar un hecho irreal, es decir, para narrar el contenido de una obra: el cuento. Bourdieu (2003), refiriéndose a la fotografía periodística, afirma que:

A decir verdad, la foto del periódico no obtiene todo su valor del valor intrínseco de lo que ella representa, sino sobre todo del carácter excepcional del encuentro entre un suceso fortuito (habitualmente dramático) y el fotógrafo: hay que estar allí en el mismo momento en que el acontecimiento se produce. (p. 208)

Esta coincidencia geográfica y temporal entre el suceso y el fotógrafo se traslada al lector de la imagen capturada, es decir, quien aprecia la foto termina sintiéndose parte de la escena como si al igual que la persona fotógrafa coincidiera en tiempo y espacio con el suceso retratado. Por tanto, al usar la fotografía como ilustración de un texto se obtendría el mismo resultado: quien lee de la obra se sentiría parte de la historia, percibiendo la escena como un evento actual y real del cual está participando activamente. La construcción de una imagen mental a través de la fotografía se lograría de forma consistente, pues la persona lectora se sentiría parte de la escena, en palabras de Bourdieu (2003): "estar allí en el mismo momento en que el acontecimiento se produce" (p. 208).

La lectura de una fotografía puede realizarse de tres formas diferentes. La primera de ellas es sin ninguna información contextual, por lo que puede obtenerse una interpretación caprichosa y deliberada. La segunda, si incluye el contexto en el proceso de lectura, permitiendo reducir el margen de error que puede tenerse al intentar interpretar la fotografía. Finalmente, la tercera no solo sugiere una lectura contextual, sino que incluye 
también una interpretación de la obra mediante el análisis de esta según las emociones que evoca y el raciocinio que quien la lee le aporta (Macmillan, 2016).

Más allá del conocimiento artístico o técnico que la audiencia tenga, la fotografía presenta un significado por sí misma, un mensaje intencional cuyo fin es el ser transmitido mediante la composición gráfica que se eligió. Es decir, se puede considerar "como una unidad discursiva que se manifiesta como un todo estructurado e indivisible de significación que puede ser actualizado por un lector o destinatario dentro de un contexto cultural" (Amador, 2004, p.225).

Ya se ha mencionado el peso que puede tener una imagen al acompañar un texto y la fotografía no es la excepción. Tal como el acompañamiento discursivo que la ilustración le aporta a la obra, la fotografía, al ser una reproducción de la realidad, le agrega a la interpretación un realismo oportuno para la construcción de imágenes mentales sobre la misma. Sin embargo, la fotografía no necesariamente debe responder a una reproducción exacta de la realidad, ya que es posible también retratar escenarios construidos solo para efectos artísticos, realizar montajes fotográficos o componer imágenes que permitan la expresión de escenarios y personas que no existen en la vida real.

Es decir, la fotografía al lado de un texto literario puede aportar realismo a la obra o puede usarse para la construcción de paisajes fantasiosos, personajes que no tienen homólogo en la realidad o escenas surrealistas creadas previamente solo en la imaginación. Esta doble posibilidad representativa de la fotografía la califica como una técnica oportuna para usarse como ilustración de una composición literaria.

Un claro ejemplo de los alcances que puede tener el uso de la fotografía en la literatura es el expuesto por Laguna (2017) cuando analiza la obra "Ambros Adelwarth" (Los emigrados) de W. G. Sebald, de la cual afirma que: "Las veintiséis imágenes que se reproducen implican al lector de manera diferente a como lo hace la narrativa, convertido en testigo visual, como el narrador -a partir de formas de inversión distintas" (p. 323). Al mismo tiempo, el autor advierte que las fotografías como elemento literario presentan riesgos como la alteración o manipulación de estas, lo que reafirma la reflexión ya expuesta en párrafos anteriores sobre la importancia de buscar la objetividad en la construcción de la imagen fotográfica. 
Lo que la persona ilustradora habría construido con tintas y lienzos, la persona fotógrafa lo hace mediante su cámara en un proceso que permite obtener resultados sumamente reales. Puede agregar al proceso artístico el uso de maquillaje, escenografía y efectos de iluminación que enriquezcan el resultado final de la toma. Sin embargo, esta no es la única ventaja del uso de esta técnica para ilustrar una obra, ya que el creciente acceso a equipo fotográfico e incluso la integración de cámaras en dispositivos móviles permite que la construcción de una fotografía no sea una práctica exclusiva del profesional en fotografía. Gracias a las TIC existentes, con elementos simples, cualquiera puede aventurarse a la creación de una imagen que ilustre el texto de su preferencia y, en el caso de los profesionales en Bibliotecología, pueden explorar la oportunidad de construir su propio material para la animación lectora a través de la imagen.

\section{Reilustración de la obra La Guardiana de la naturaleza y sus amigos salvan el río}

Un ejemplo de cómo utilizar la fotografía como método de ilustración de un libro álbum es el realizado por el presente autor con la obra La Guardiana de la naturaleza y sus amigos salvan el río. Dicho procedimiento se realizó en el marco del Trabajo Final de Investigación Aplicada para optar por el grado de Máster en Bibliotecología y estudios de la información con énfasis en Tecnologías de la Información, impartido en la Universidad de Costa Rica.

Siempre que se desee tomar fotografías para ilustrar una obra es necesario determinar qué elementos compondrán cada una de las capturas, quiénes interpretarán los personajes de la obra, cómo se accedería a locaciones que representen los lugares descritos y cómo se gestionará el vestuario y la utilería. La forma de resolver estas necesidades puede vincular la participación de terceros, la visita a lugares y la compra de ropa y artículos de decoración, o bien, puede realizarse también la construcción a escala de los personajes, escenarios y otros elementos que interactúan en la obra. A continuación, se describe cómo se desarrolló esta etapa de la reilustración mediante la representación a escala de la obra.

\section{a. Representación a escala de la obra}

La obra La Guardiana de la naturaleza y sus amigos salvan el río, escrita por Jessica Sheffield e ilustrada por Shanon McWhirter, cuenta la historia de Lucía, una niña de nueve años que descubre que el río de su comunidad está contaminado y decide buscar la 
manera de salvarlo. La obra incluye varios personajes menores de edad, varios adultos, locaciones en el exterior y en el interior y diferentes objetos como bicicletas, muebles, columpios, entre otros. La cantidad de elementos necesarios para realizar las fotografías exigieron esfuerzos significativos en tiempo, dinero y logística para lograr reproducir todos los eventos de la obra.

Para simplificar los costos de producción se decidió representar el cuento en reproducciones a escala a través de la construcción de una maqueta. Dicha maqueta se acompañó con personajes fabricados con plastilina, así como otros objetos importantes para reproducir la ilustración, tales como bicicletas, animales del bosque, muebles, residuos, entre otros. A continuación, se detalla el proceso de diseño y construcción de la maqueta, así como de los personajes y los elementos adicionales necesarios.

\section{b. Elaboración de la maqueta}

Las ilustraciones realizadas por McWhirter incluyen seis personajes: dos niñas llamadas Lucía y Ana, dos niños: Kai y Lucas, y dos adultos: la señorita Ericka, maestra de Lucía, y el señor Saldana, director de la escuela. Los hechos que narra el cuento se desarrollan en nueve locaciones diferentes: el río, los alrededores de la escuela, los alrededores del río, el camino a la escuela, la oficina del director, un árbol con un columpio de llanta, la habitación de Lucía, un kiosco y el interior de la escuela.

Se dispuso, por lo tanto, que en una misma maqueta pudieran representarse todos estos escenarios, por lo que se diseñó un croquis que graficara la distribución de locaciones que tendría la maqueta según el número de página del libro original. Una vez elaborado el croquis se procedió a construir la base de la maqueta, cuyas dimensiones serían de 174 $\mathrm{cm}$. $x 74 \mathrm{~cm}$. Las ideas para la elaboración de la base de la maqueta fueron tomadas del tutorial titulado "Maqueta: LAGO" de María Amora (2016): https://youtu.be/sX6752BxEWY (publicado el 25 de abril de 2016). Por su parte, para la elaboración de edificios y otros elementos que debía contener la maqueta (La escuela, el kiosco, las bancas, las sillas, la repisa, el estante y las mesas) se construyeron con una lámina de madera comprimida conocida como MDF. 
Asimismo, se crearon árboles y vegetación, utilizando materiales como alambre flexible, cinta de enmascarar (masking tape), esponja y pinturas en acuarela. El procedimiento para construir árboles se tomó de dos tutoriales diferentes. El tutorial para la elaboración del tronco está disponible en https://youtu.be/bcQrQn9 yQs y el tutorial para la elaboración del follaje en https://youtu.be/d-aLaacfab8.

Como se mencionó anteriormente, en el cuento participan seis personajes, algunos, como la protagonista Lucía, participan en repetidas ocasiones, con vestuarios diferentes y en posiciones diferentes, por lo que se decidió, para ganar movilidad de las personas a la hora de tomar las fotografías, construirlos en plastilina y elaborar su ropa a mano o en máquina de coser. Esta decisión permitió que todos los personajes fueran flexibles para colocarlos en diferentes posiciones dentro de la maqueta. (Ver Figura 1).

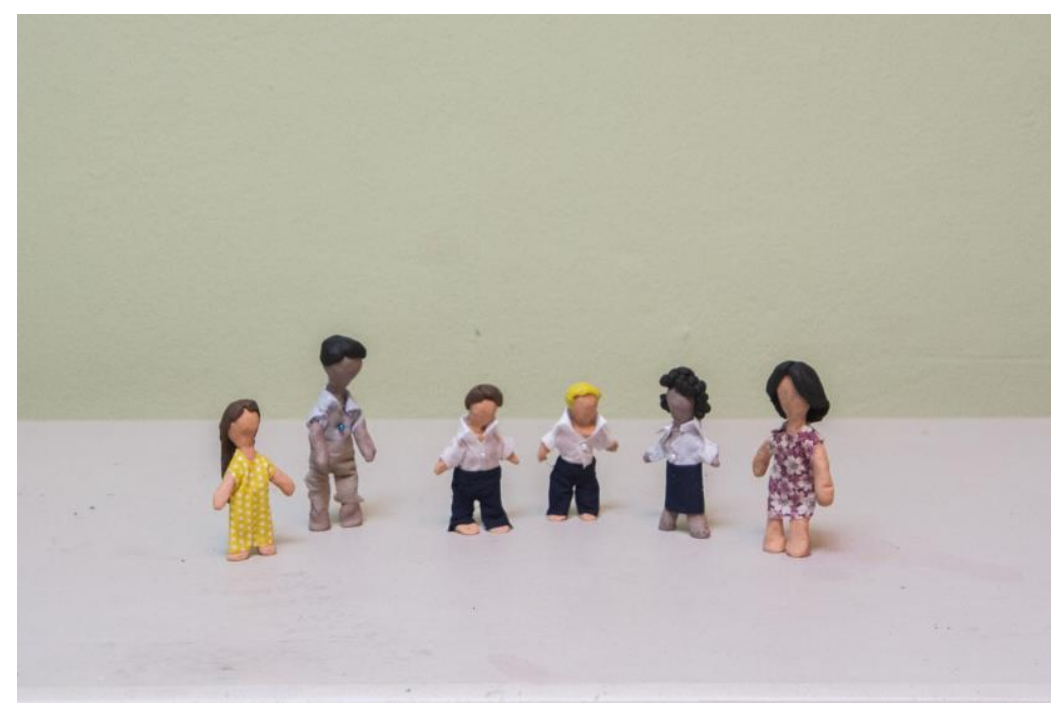

Figura 1: Personajes terminados

Fuente: Elaboración propia.

Las ideas para la confección de las figuras de los personajes se utilizaron de los tutoriales https://youtu.be/7eOpuTZI2mU y https://youtu.be/nIP7N2s7PPQ, y los contenidos impartidos en el curso virtual "Confeccionando ropa miniatura" ofertado por el sitio web www.domestika.com.

En relación con los animales del cuento, en este pueden verse aves, mariposas, una tortuga y un conejo. Todos fueron confeccionados con origami, es decir, el arte de doblar papel para que adquiera formas atractivas. Para confeccionar las aves se utilizó el tutorial disponible en 
https://youtu.be/qYzCaTbURQ4. Para la tortuga se utilizó el tutorial disponible en https://youtu.be/S H9nZiludY, para el conejo el tutorial https://youtu.be/Zv1utMTLtoA, para la caja el tutorial https://youtu.be/caDwbe02l6g y para las mariposas se utilizó el tutorial disponible en https://youtu.be/SiAkOp2W9MY.

Finalmente, para la confección de las bicicletas con las cuales Lucía y sus amigos salen a buscar residuos por el bosque se utilizó la técnica de impresión 3D y el software Tinkercad, una aplicación gratuita que permite la modelación de objetos en 3D. Una vez diseñada la bicicleta se imprimió su marco y sus ruedas por aparte, para luego ser pintadas con acuarela y ensambladas con silicón caliente. El producto final puede apreciarse en la Figura 2.

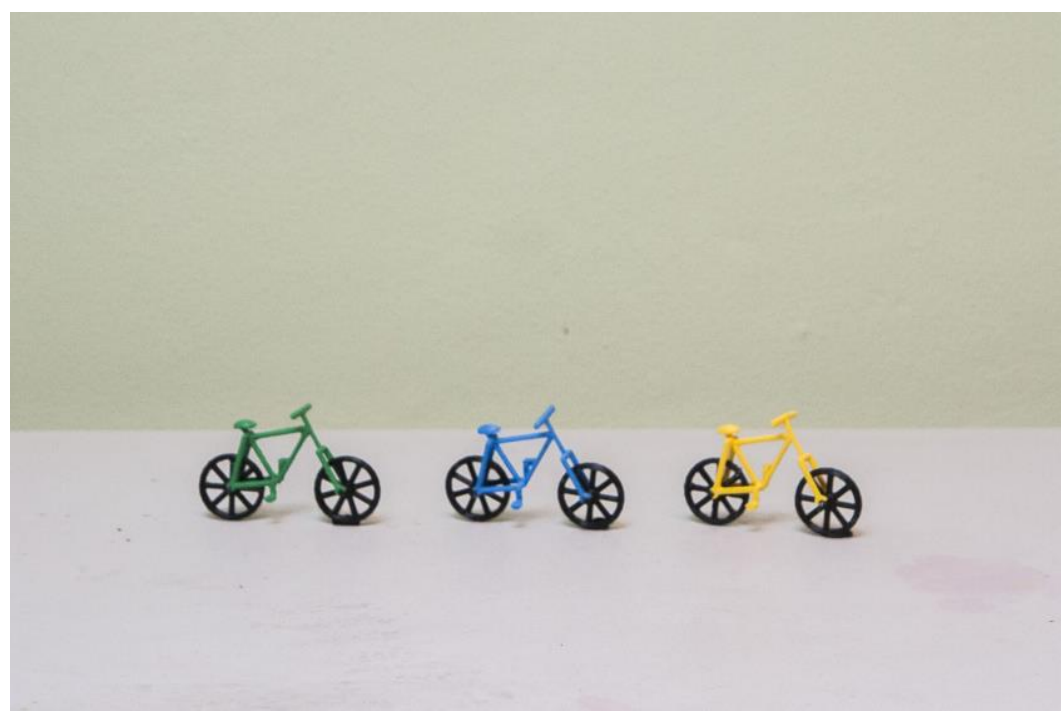

Figura 2. Bicicletas impresas en 3D Fuente: Elaboración propia.

Al terminar de elaborar todos los elementos para reproducir las escenas del cuento se procedió a agregarlos todos a la maqueta, teniendo como resultado una reproducción a escala de todas las locaciones necesarias para ilustrar el cuento. Además, se filmó un vídeo que documenta todo el proceso de construcción de la maqueta y se publicó en la red social YouTube, a través del enlace https://youtu.be/AmssyAnA338

Finalmente, para dar un efecto de profundidad y contextualizar aún más cada uno de los escenarios elaborados se imprimió una fotografía panorámica de $180 \times 60 \mathrm{~cm}$, tomada sobre la ruta a Ciudad Quesada, en San Carlos de Alajuela, con el fin de colocarla en el 
fondo de cada locación y poder obtener un resultado más realista en cada imagen. La fotografía es el resultado de la unión de seis disparos tomados con una diferencia de 30 grados de giro sobre el propio eje del fotógrafo (Ver Figura 3).

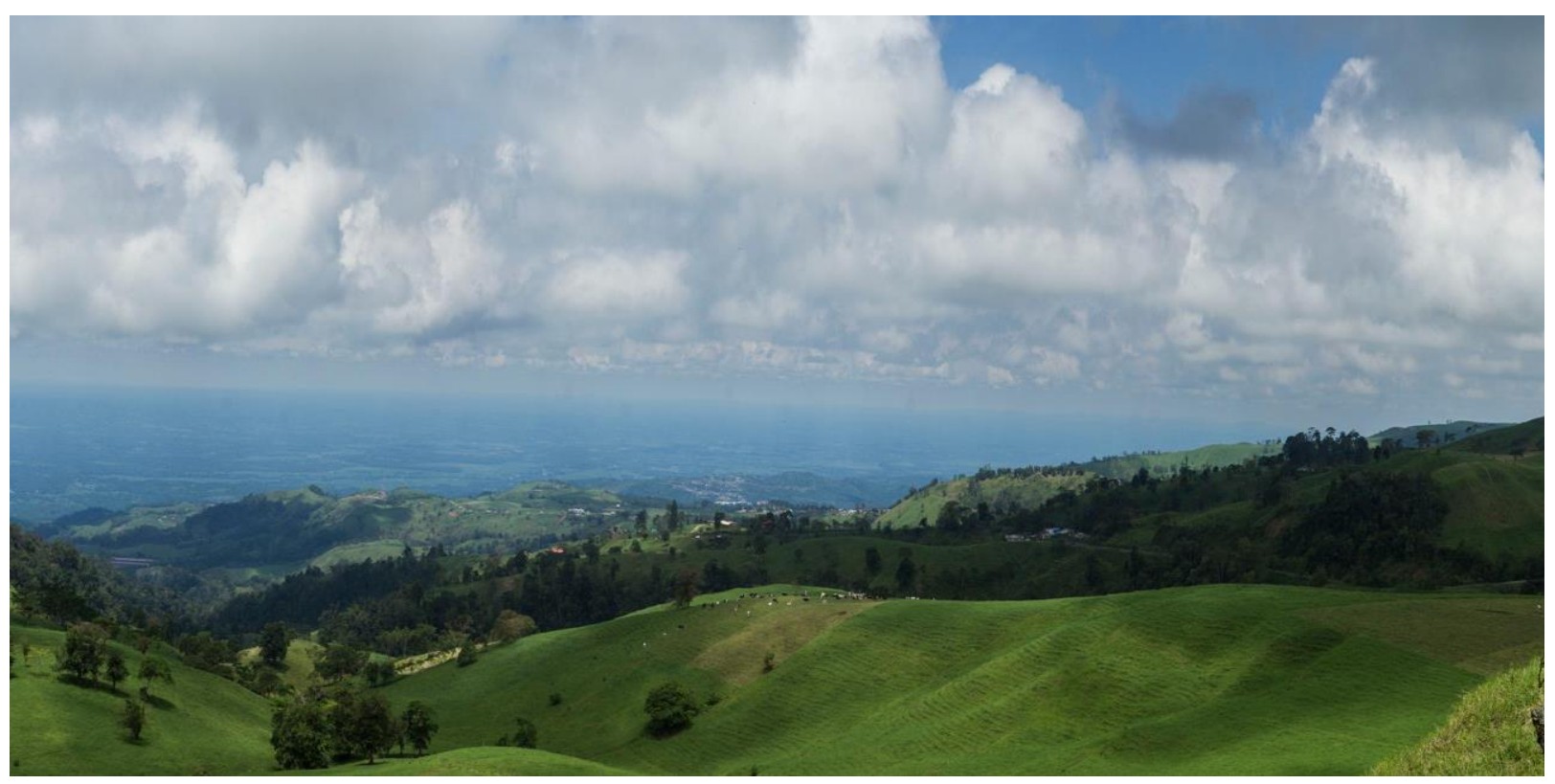

Figura 3. Fotografía de fondo

Fuente: Elaboración propia.

La maqueta, junto con la fotografía de fondo y todos los elementos elaborados para la reproducción de los escenarios se colocaron de forma tal que permitiera la fácil manipulación de los personajes con sus accesorios y la movilidad del investigador para realizar las capturas fotográficas (Ver Figura 4).

\section{a. Captura de fotografías}

Para la captura de las fotografías de las ilustraciones se tomó como referente las imágenes originales del libro, con el fin de determinar cuáles eran las locaciones por capturar, qué personajes interactúan en cada imagen y qué elementos adicionales debían incluirse. Se utilizó una cámara Canon 7D, de 18 megapíxeles, con un sensor APS-C y se configuró su modo manual de forma tal que los valores de captura fueran F9, para el nivel de apertura del diafragma de la cámara, esto con el fin de obtener un buen enfoque de los personajes; velocidad de $1 / 100$, para evitar barridos o fotos movidas, balance de blancos en su ajuste de "Flash", ya que las escenas serían iluminadas con una luz adicional de flash y un valor 
de ISO de 3200 , el cual permite obtener una cantidad oportuna de luz sin causar problemas de nitidez en la imagen final.

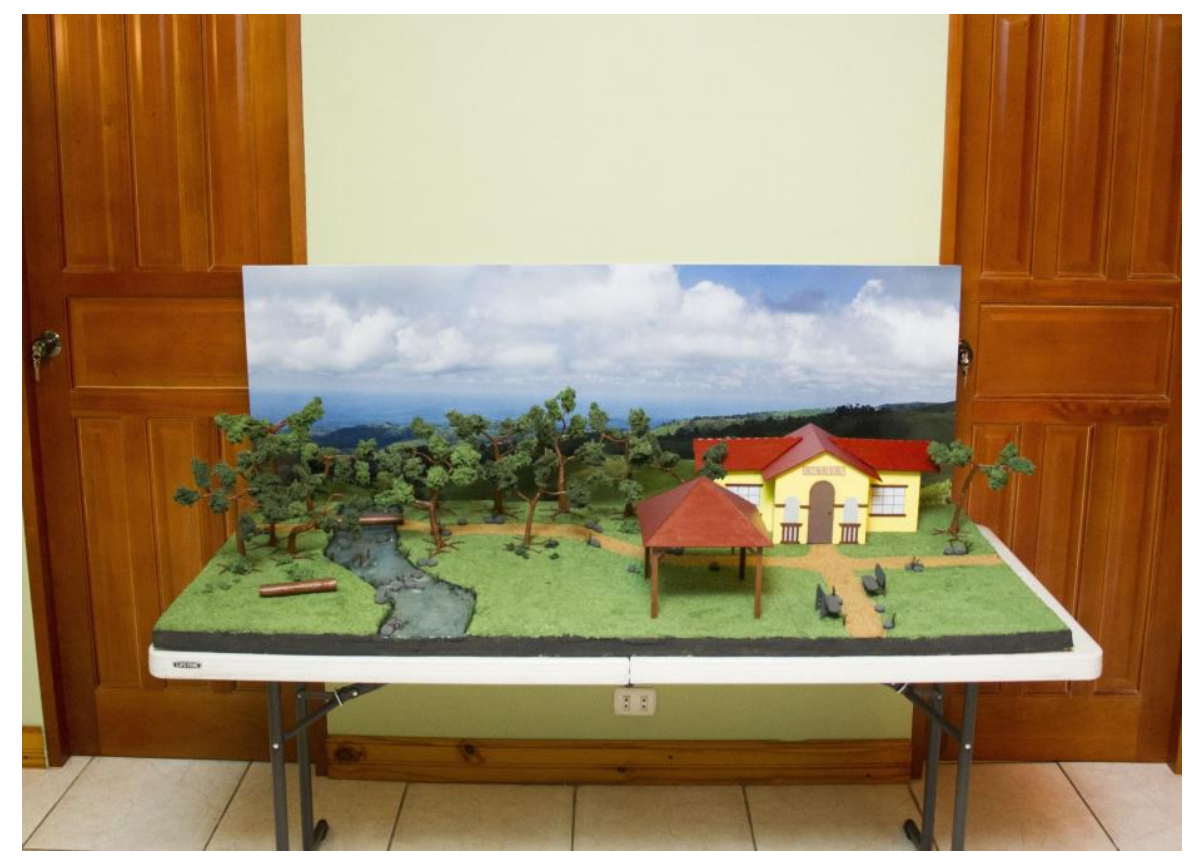

Figura 4. Maqueta con fotografía de fondo

Fuente: Elaboración propia.

Además, como esquema de iluminación de las fotografías se utilizó un Flash marca Yongnuo modelo YN 480, el cual se configuró para que disparara a distancia, es decir, con un sistema de mando por ondas de radio que permite el disparo sincronizado del Flash sin necesidad de colocarlo sobre la cámara, y se instaló al lado de la maqueta apuntando el disparo al techo de la habitación. Esta configuración se utilizó para que la luz rebotara en el cielo raso del cuarto y se devolviera de forma perpendicular a la maqueta, tal cual sucede con la luz del sol. A continuación, en el Cuadro 1 se presenta la comparación entre la descripción de las ilustraciones originales del cuento y las nuevas fotografías capturadas: 
Bibliotecas. Vol. 38, № 2, julio - diciembre, 2020. EISSN: 1659-3286

URL: http://www.revistas.una.ac.cr/index.php/bibliotecas/index

\section{Cuadro 1}

Distribución por página de fotografías capturadas para ilustración del libro

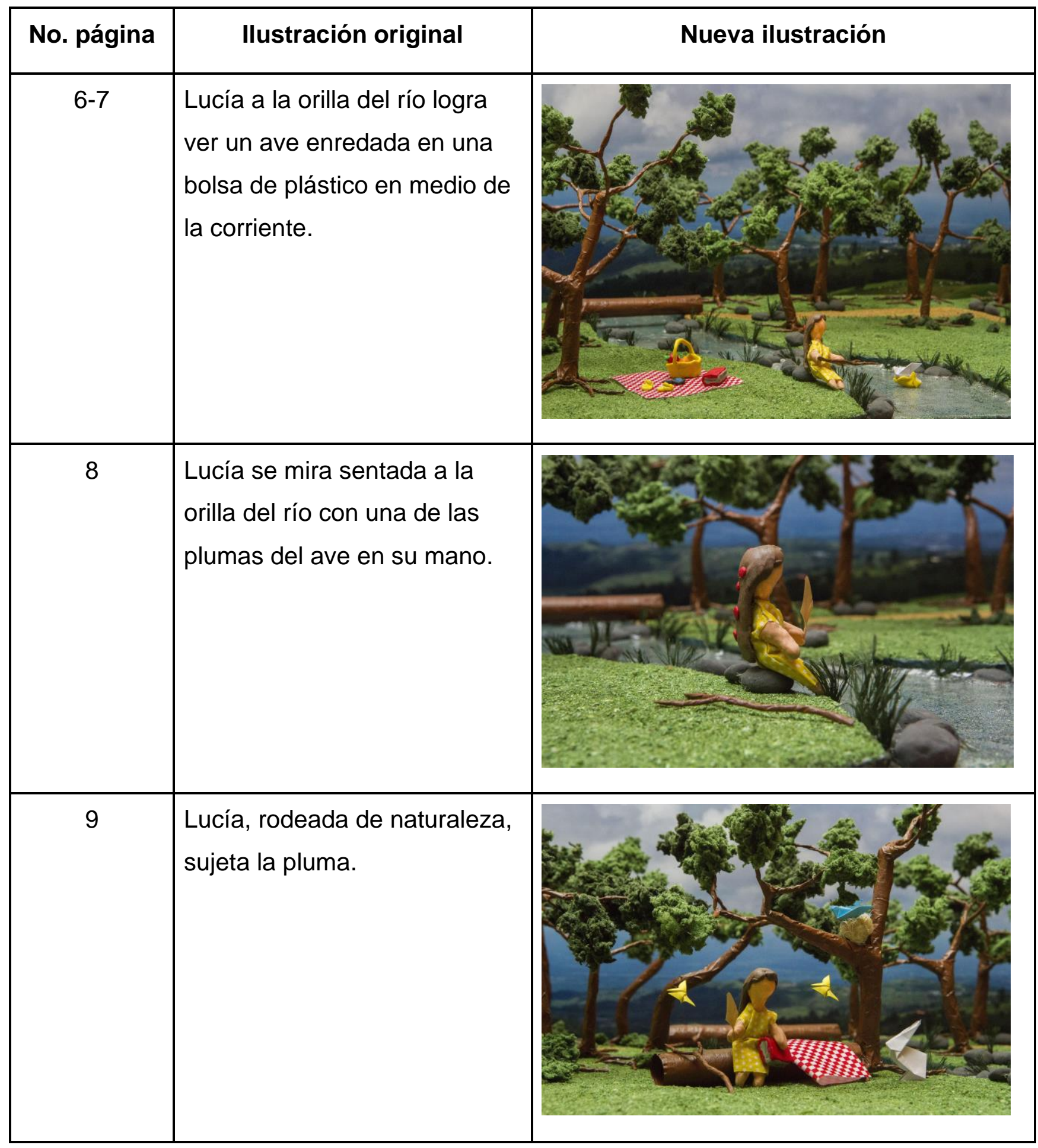


Bibliotecas. Vol. 38, № 2, julio - diciembre, 2020. EISSN: 1659-3286

URL: http://www.revistas.una.ac.cr/index.php/bibliotecas/index

\begin{tabular}{|l|l|l|}
\hline 10-11 & $\begin{array}{l}\text { Vista aérea del pueblo, con } \\
\text { marcas sobre los lugares } \\
\text { donde existen desechos } \\
\text { tirados. }\end{array}$ & $\begin{array}{l}\text { Desembocadura de diferentes } \\
\text { ríos contaminados que llevan } \\
\text { desechos al mar. }\end{array}$ \\
\hline 12 & $\begin{array}{l}\text { La imagen del planeta tierra } \\
\text { con animales sufriendo por los } \\
\text { desechos. }\end{array}$ \\
\hline 13 & & \\
\hline
\end{tabular}


Bibliotecas. Vol. 38, №2, julio - diciembre, 2020. EISSN: 1659-3286

URL: http://www.revistas.una.ac.cr/index.php/bibliotecas/index

\begin{tabular}{|l|l|l|}
\hline $14-15$ & $\begin{array}{l}\text { Lucia, Ana, Kai y Lucas } \\
\text { juegan en un árbol. }\end{array}$ & $\begin{array}{l}\text { Lucía se reúne con su } \\
\text { maestra y el director de su } \\
\text { escuela en la oficina de este. }\end{array}$ \\
\hline 16 & $\begin{array}{l}\text { Lucía se columpia en un } \\
\text { neumático que cuelga del } \\
\text { árbol del jardín de su escuela. }\end{array}$ & $\begin{array}{l}\text { Lucía, Ana y Kai recogen la } \\
\text { basura a la orilla del río, } \\
\text { mientras Lucas los observa } \\
\text { con atención. }\end{array}$ \\
\hline $17-18$ & & \\
\hline 19 & &
\end{tabular}


Bibliotecas. Vol. 38, №2, julio - diciembre, 2020. EISSN: 1659-3286

URL: http://www.revistas.una.ac.cr/index.php/bibliotecas/index

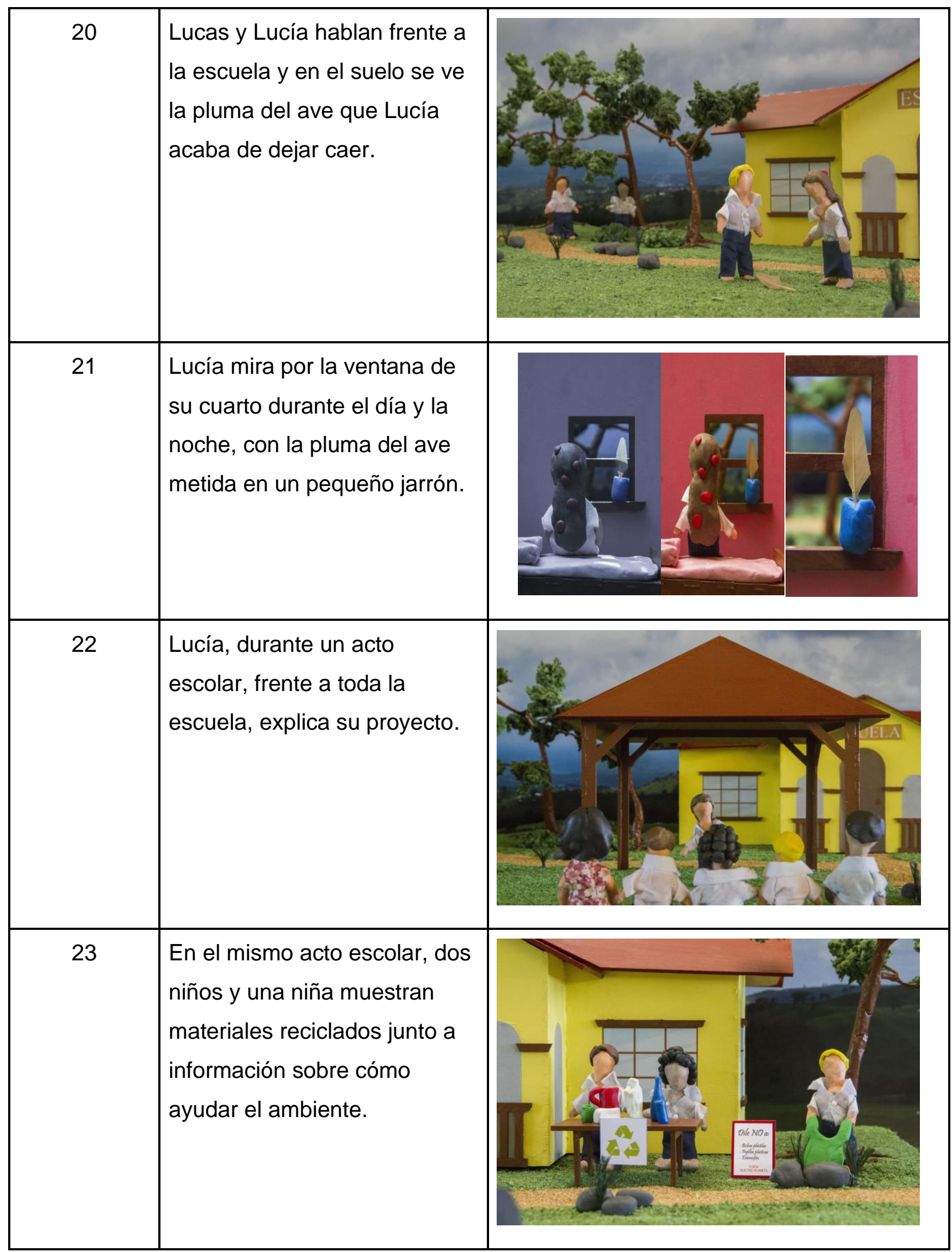




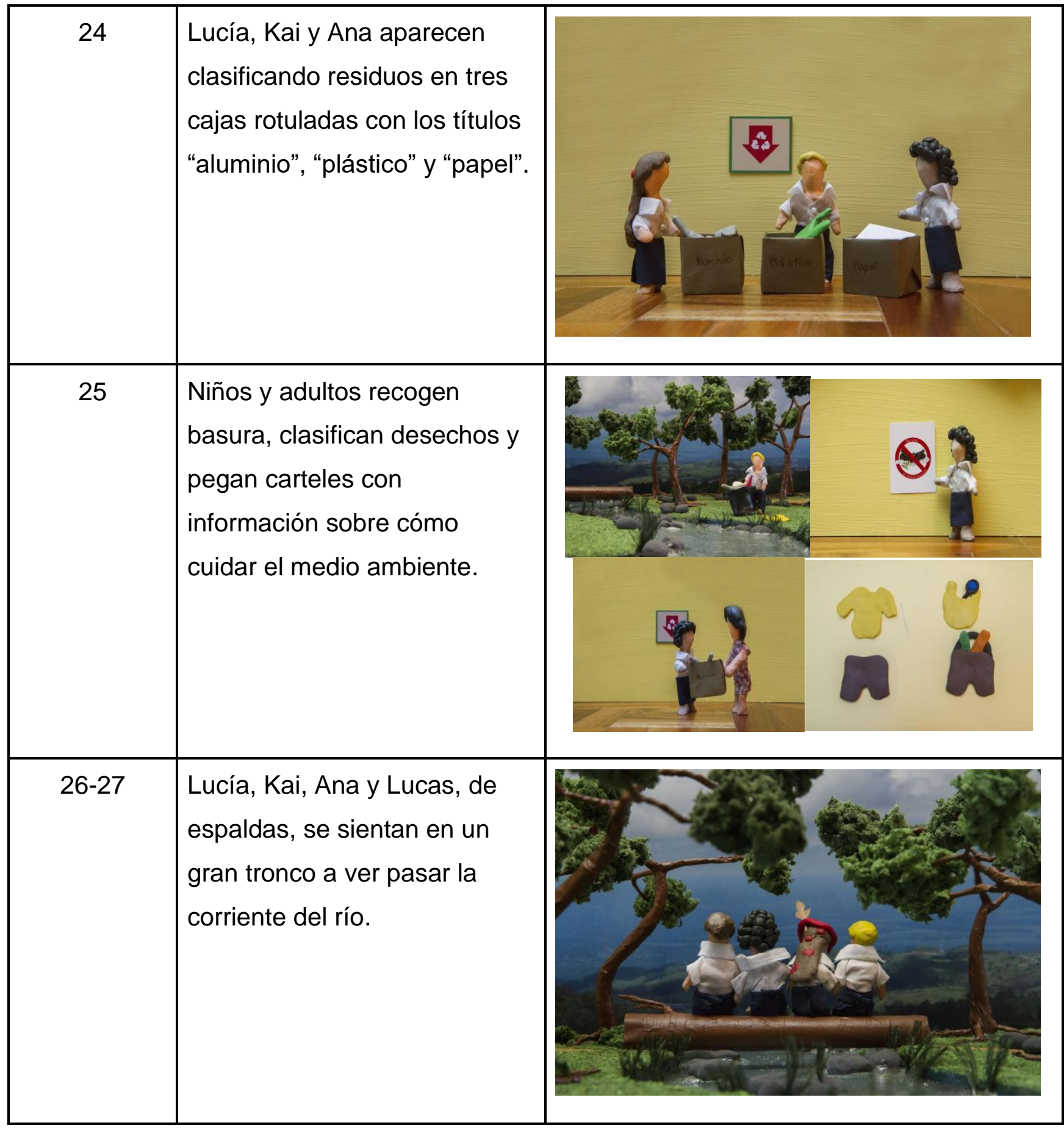

Fuente: Elaboración propia del autor, 2020.

En el caso de las fotografías correspondientes a las páginas 10, 11 y 12, se decidió cambiar la ilustración para poder utilizar únicamente la maqueta diseñada y no invertir más tiempo y recursos en la elaboración de una maqueta de todo el pueblo o de ríos desembocando en la playa. Todas las fotografías capturadas se editaron mediante la aplicación Adobe Photoshop, permitiendo el retoque de manchas en la plastilina, hilos sueltos en la costura, mejoras en el color, la luz, el enfoque y el contraste. Tras dicha edición se exportaron 
todas las fotografías al formato JPG, en calidad 12, y se colocaron en una misma carpeta para ser utilizadas posteriormente en la diagramación del documento.

\section{b. Diagramación de la obra}

Para la diagramación del documento se utilizó el software Adobe InDesign, el cual permitió la integración de texto, ilustraciones, y marcadores de realidad aumentada. Es importante mencionar que la diagramación de un documento requiere de una planificación detallada en la que se definan la disposición de todos los elementos con los que interactuará el lector. Dicha planificación debe contar con la armonía necesaria para que la consulta de la obra sea agradable. Según Guerrero (2016): "Las publicaciones dependen de ciertas características para componer la diagramación y maquetación. No es simplemente acomodar elementos por donde se quiera, todo debe llevar una armonía que se debe respetar para que sea entendible" (p. 42).

El mismo Guerrero (2016) afirma que dicha diagramación debe componerse por columnas, es decir, los recuadros donde se ubica el cuerpo del texto; márgenes, que son los espacios en blanco que todo documento debe tener para que su contenido sea agradable de leer; sangrado, que es el exceso de tinta adicional que permite tener impresiones con contenido de borde a borde de cada página; y finalmente páginas, las cuales son el soporte sobre el cual está plasmada toda la diagramación. Todos estos elementos se planifican en una plantilla llamada retícula, que es un diseño básico que muestra la composición que llevará el texto, las imágenes y cualquier otro elemento que tenga una obra, su conformación se basa en "líneas verticales y horizontales que le dan orden y equilibrio a la composición de la página y que son la base para la diagramación" (Guerrero, 2016, p. 33).

La nueva versión de la obra La guardiana de la naturaleza y sus amigos salvan el río se creó con una dimensión de $19 \times 20 \mathrm{~cm}$. por página, un total de 44 páginas, equivalente a 22 pliegos, de los cuales 8 fueron utilizados para las páginas preliminares y la portada y 14 para las páginas que contienen el cuento escrito por Sheffield. Cada una de las páginas estará compuesta por 6 columnas guías, que permitirán definir la distribución espacial de los elementos de la obra. 
Tras la diagramación completa de la obra se exportó el documento con la opción Print Booklet, la cual permite generar un archivo PDF con la distribución de las páginas en el orden necesario para compaginarse y las marcas de corte para eliminar de la impresión el contenido que está fuera del área de sangrado. Dicho archivo en PDF se imprimió a color, se guillotinó según las líneas de corte, se encuadernó con una grapa en el centro y se presentó al comité asesor de la presente investigación para su validación.

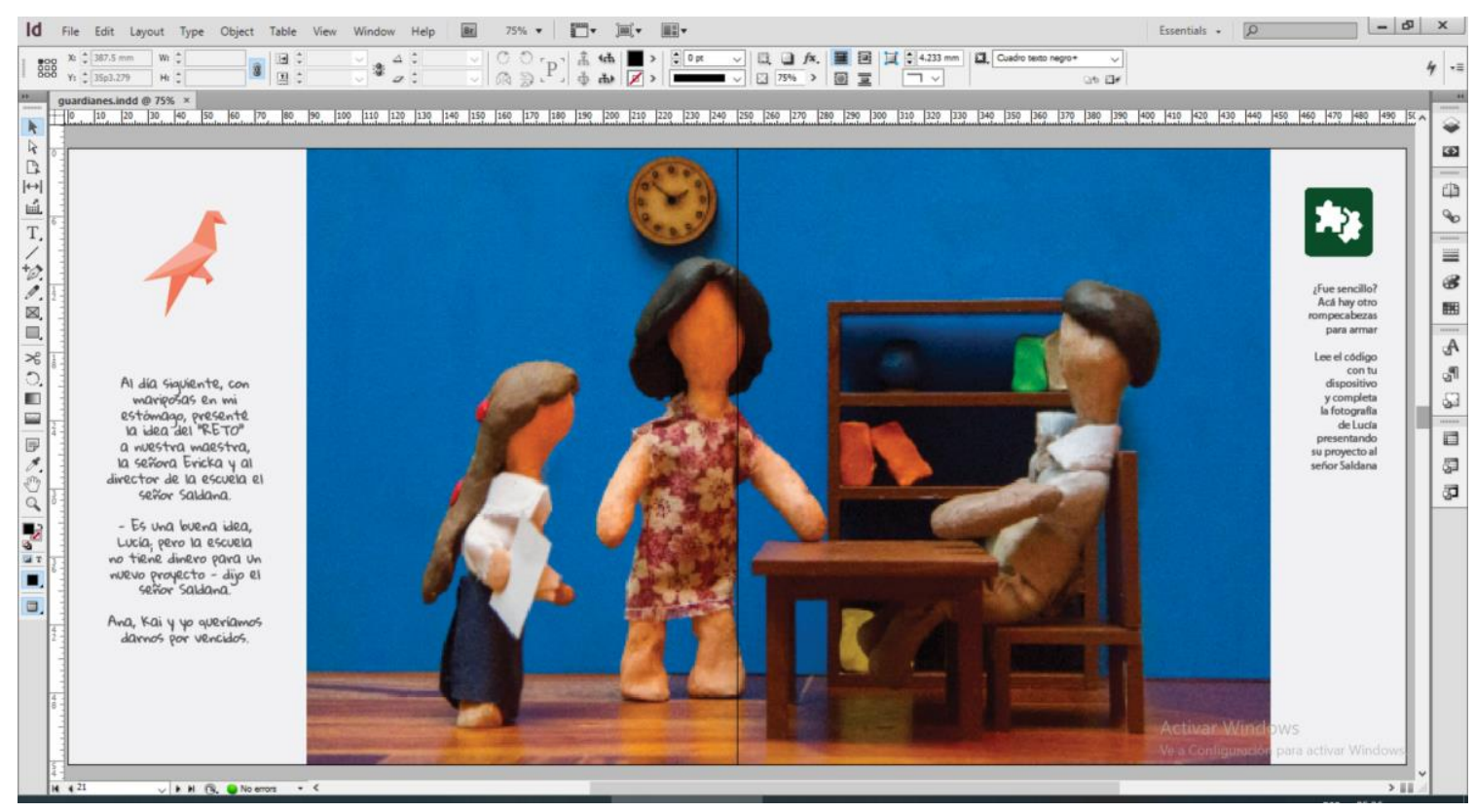

Figura 5. Diagramación de la obra

Fuente: Elaboración propia.

\section{Conclusiones}

La técnica de ilustración mediante el uso de la fotografía permite aprovechar las potencialidades de la imagen con respecto a los procesos cognitivos que genera. Desde la ilustración de un cuento hasta el acompañamiento gráfico durante el desarrollo de los contenidos evaluados en un salón de clase son parte de las ventajas que la fotografía digital puede aportar.

Es posible crear, desde las bibliotecas, material de animación lectora haciendo uso de la fotografía como método de ilustración. En este sentido es importante indicar que no se necesita equipo especializado, la cámara de un dispositivo móvil puede ser de gran utilidad; sin embargo, se recomienda tener conocimientos básicos de composición fotográfica, o bien utilizar fotografías de terceros que estén disponibles para su libre uso en Internet. 
Para la creación de ilustraciones originales se concluye que la opción de crear escenarios a escala para su posterior captura fotográfica es muy viable, pues permite reducir el tiempo invertido en la búsqueda del escenario que se apegue al cuento y de modelos que deseen interpretar a los personajes, en especial si se tratan de personajes menores de edad.

El libro álbum, como recurso para la animación lectora, debe verse como un producto complejo, que combina el texto y la imagen como lenguajes relacionados para contar una historia. Debe además concebirse como un elemento de interdependencia entre ambos lenguajes, de forma tal que la historia no sería la misma si al texto le faltan las imágenes o viceversa.

Finalmente, las bibliotecas pueden encontrar en las nuevas Tecnologías de la Información y Comunicación oportunidades para diversificar su oferta de productos y para la creación de recursos para la animación lectora. Es importante que las unidades de información aprovechen estas oportunidades para diseñar productos de vanguardia que capturen la atención de los usuarios y visibilicen a las bibliotecas como organizaciones vivas en la nueva Sociedad de la Información y Conocimiento.

\section{Referencias bibliográficas}

Abad-Molina, J. (2012). Imagen-palabra: texto visual o imagen textual. En: IV Congreso Iberoamericano de las Lenguas en la Educación y en la Cultura. España. Recuperado de: https://www.oei.es/historico/congresolenguas/comunicacionesPDF/Abad Javier.pdf Amador, P. (2004). La imagen fotográfica y su lectura. Segundas Jornadas Imagen, Cultura y Tecnología. Madrid: Universidad Carlos III, Editorial Archiviana. 225-239. Recuperado de https://core.ac.uk/download/pdf/30042969.pdf

Barthes, R. (1990). La cámara lúcida. Nota sobre la fotografía. Buenos Aires, Argentina: Ediciones Paidós.

Recuperado

de:

https://monoskop.org/images/c/c9/Barthes Roland La camara lucida Nota sobre la fotografia.pdf

Bourdieu, P. (2003). Un arte medio: ensayo sobre los usos sociales de la fotografía. España, Barcelona: Editorial Gustavo Gili S.A.

Chiuminatto, M. (2011). Relaciones texto-imagen en el libro álbum. Revista UNIVERSUM 26 (1), 59-77. Recuperado de https://scielo.conicyt.cl/pdf/universum/v26n1/art 04.pdf 
Colomer, T. (2005). Las funciones de la literatura infantil y el contexto actual. En Lectura y literatura infantil y juvenil: claves. España: Aljibe.

Delgado, S. (2014) La importancia de la imagen en la literatura infantil: una propuesta didáctica. Trabajo final de grado. Universidad de Jaén. Facultad de Humanidades y Ciencias de la Educación. Recuperado de http://tauja.ujaen.es/bitstream/10953.1/1360/1/TFG DelgadoSanchez\%2cSilvia.pdf

Fajardo, D. (2014). El potencial didáctico del libro-álbum para la educación literariaintercultural. Educar em Revista. 52, 45-68. Recuperado de http://www.scielo.br/pdf/er/n52/04.pdf

Gutiérrez, C. (2013). La fotografía como recurso en la literatura. E-innova BUCM (29). 1-8. Recuperado de: https://biblioteca.ucm.es/BUCM/revcul/e-learning-innova/29/art1333.pdf Higuera, G. (2016) De la estética de la recepción a la animación a la lectura: consideraciones teóricas para una propuesta de animación de la lectura literaria en espacios no convencionales. La Palabra, 28. 187-199.

Hoster, B. y Gómez, A. (2013). Interpretación de álbumes ilustrados como recurso educativo para la competencia literaria y visual. Red Visual 19. 65-76. Recuperado de https://dialnet.unirioja.es/servlet/articulo?codigo=4749654

Laguna, A. (2017). El artefacto mnemotécnico, literatura y fotografía en W. G. Sebald. Castilla estudios de literatura (8). 308-338. Recuperado de: https://uvadoc.uva.es/bitstream/10324/24149/1/Castilla-2017-8-ArtefactoMnemotecnico.pdf

Macedo, A. (2011). Literatura y Fotografía: El diálogo entre palabras e imagen. En II Congreso Internacional de Literatura y Cultura Españolas Contemporáneas, La Plata, Argentina. Diálogos Transatlánticos. Disponible en: http://www.memoria.fahce.unlp.edu.ar/trab eventos/ev.2826/ev.2826.pdf

Mac-Millan, M. (2016). Acerca de la legilibilidad de la fotografía y El arte de visibilizar la pregunta (Koen Wessing). Aisthesis, 60. 129-143. Recuperado de http://www.redalyc.org/pdf/1632/163249379007.pdf

Guerrero, L. (2016). El diseño editorial. Guía para la realización de libros y revistas. Recuperado de https://eprints.ucm.es/39751/1/TFM\%20\%20autor\%20Leonardo\%20Guerrero\%20Reyes.pdf

Puerto, M. (2015). Leer con imágenes, dibujar con palabras. La comprensión lectura mediada por el libro álbum. Trabajo de grado para optar a Magíster en Pedagogía de la Lengua Materna. Universidad Distrital Francisco José de Caldas. Recuperado de: http://repository.udistrital.edu.co/bitstream/11349/2135/1/PuertoRubioMarthaLiliana2015.pdf 
Ríos, V. (2009). La fotografía como clave de lectura de La nueva novela. Estudios Filológicos 44. 53-65. Recuperado de https://scielo.conicyt.cl/pdf/efilolo/n44/art03.pdf Sánchez, H. (2009). Una imagen enseña más que mil palabras ¿ver o mirar? Zona Próxima 10. 198-209. Recuperado de https://dialnet.unirioja.es/descarga/articulo/3223208.pdf Sontag, S. (2006). Sobre la fotografía. México: Alfaguara.

Suárez, H. (2008). La fotografía como fuente de sentidos. Cuaderno de Ciencias Sociales 150. Costa Rica, FLACSO. Recuperado de: https://issuu.com/hugo_jose_suarez/docs/la_fotografia_como_fuente_de_sentidos UNESCO. (2013). Enfoques estratégicos sobre las TICS en educación en América Latina y el Caribe. Recuperado de

http://www.unesco.org/new/fileadmin/MULTIMEDIA/FIELD/Santiago/images/ticsesp.pdf Unidad de Currículum y Evaluación. (2007). Ver para leer. Acercándonos al libro álbum. Santiago de Chile: Ministerio de Educación. Recuperado de https://curriculumnacional.mineduc.cl/614/w3-article-83560.html

\section{Notas del Autor}

* Académico de la Escuela de Bibliotecología y Ciencias de la Información, Universidad de Costa Rica. Correo electrónico: jairo.guadamuz@ucr.ac.cr ORCID ID: https://orcid.org/0000-0002-0284-3656.

${ }^{1}$ Este artículo es una obra derivada del Trabajo Final de Investigación Aplicada "Creación de un libro álbum con realidad aumentada de la obra La guardiana de la naturaleza y sus amigos salvan el río como apoyo al proyecto Verde que te leo verde de la Fundación Leer / IBBY Costa Rica. 